\title{
O PAPEL PEDAGÓGICO DO COORDENADOR E A FORMAÇÃO CONTINUADA DE PROFESSORES CENTRADA NA ESCOLA
}

\author{
Juliana Pedroso Bruns ${ }^{1}$ \\ Eliani Aparecida Busnardo Buemo2 \\ Rita Buzzi Rausch ${ }^{3}$
}

\section{RESUMO}

Esta pesquisa teve por objetivo, analisar o papel do coordenador pedagógico na formação continuada de professores centrada na escola, em um Colégio da rede privada de ensino, localizado em uma cidade do interior do Vale do Itajaí (SC). Foi realizada durante o Estágio Supervisionado em Gestão Escolar do curso de Licenciatura em Pedagogia. A pesquisa caracteriza-se por ser qualitativa e de campo. Participaram da pesquisa 13 professores que atuavam no Ensino Fundamental I. Aplicou-se inicialmente um questionário com o objetivo de conhecer os interesses dos professores acerca de temas pedagógicos, para posteriormente ser realizado um momento de formação com eles. Para dialogar com a temática proposta no âmbito da formação continuada de professores, utilizou-se das contribuições de Garcia (1992), Imbernón (2010, 2011), André (1999, 2015), Vaillant e Marcelo (2015), Gatti (2013), Gatti et al. (2019) e Nóvoa (2009). Os resultados evidenciaram que a formação continuada é imprescindível para a qualidade do ensino. No entanto, no dia da formação, mesmo os professores relatando que estariam presentes, muitos não compareceram. Tal acontecimento nos faz refletir que não basta apenas o coordenador pedagógico do Colégio propiciar momentos de formação para seu grupo de professores, mas é necessário que haja uma parceria colaborativa dentro das instituições de ensino e uma consciência de autoformação dos professores.

Palavras-chave: Coordenação pedagógica. Formação continuada de professores. Formação centrada na escola.

\section{THE COORDINATOR'S PEDAGOGICAL ROLE AND CONTINUED TEACHER EDUCATION CENTRED IN THE SCHOOL}

\footnotetext{
1 Mestranda em Educação no Programa de Pós-Graduação da Universidade Regional de Blumenau - (PPGE-FURB), Brusque, SC, Brasil. Orcid iD: https://orcid.org/0000-0002-9310-1892. E-mail: julianap.bruns@gmail.com

2 Mestre em Educação pela Universidade Estadual do Centro-Oeste. Secretária Municipal de Educação no Município de Brusque. Professora do Centro Universitário de Brusque -UNIFEBE, Brusque, SC, Brasil. Orcid iD: https://orcid.org/0000-0002-2195-4634. E-mail: eliabb@unifebe.edu.br

3 Doutora em Educação pela UNICAMP e Pós-doutorado em Educação pela UFSC. Professora visitante no Programa de Pós-Graduação em Educação da UNIVILLE e no Programa de Pós-Graduação em Educação da FURB, Blumenau, SC, Brasil. Orcid iD: https://orcid.org/0000-0002-9413-4848. E-mail: ritabuzzirausch@gmail.com
} 


\section{ABSTRACT}

This research aimed to analyze the role of the pedagogical coordinator in the continued education of teachers centered at the school, in a private school, located in a city in the countryside of Vale do Itajaí (SC). It was carried out during the Supervised Internship in School Management of the Pedagogy Degree course. The research is characterized by being qualitative and field. Thirteen teachers who worked in the elementary school participated in the research. A questionnaire was initially applied with the objective of knowing the interests of teachers about pedagogical themes and a moment of educating them afterwards. In order to dialogue with the theme proposed in the context of continued teacher education contributions from Garcia (1992), Imbernón (2010, 2011), André (1999, 2015), Vaillant and Marcelo (2015), Gatti (2013), Gatti et al. (2019) and Nóvoa (2009). The results showed that continued education is essential for the quality of teaching. However, on the day of the education, even though the teachers reported that they would be present it, many of them did not attend it. Such an event makes us reflect that it is not enough for the College's pedagogical coordinator to provide education moments for its group of teachers, but it is necessary that there is a collaborative partnership within teaching institutions and an awareness of teachers' self-education.

Keywords: Continued teacher education. Pedagogical coordination. School.

\section{EL PAPEL PEDAGÓGICO DEL COORDINADOR Y LA FORMACIÓN CONTINUA CENTRADA EN EL PROFESORADO}

\section{RESUMEN}

Esta investigación tuvo como objetivo analizar el papel del coordinador pedagógico en la educación continua de los docentes centrados en la escuela, en una escuela privada, ubicada en una ciudad en el interior del Vale do Itajaí (SC). Se llevó a cabo durante la pasantía supervisada en gestión escolar de la carrera de pedagogía. La investigación se caracteriza por ser cualitativa y de campo. Trece docentes que trabajaban en la escuela primaria participaron en la investigación, inicialmente se aplicó un cuestionario con el objetivo de conocer los intereses de los docentes sobre temas pedagógicos, para luego tener un momento de capacitación con ellos. Para dialogar con el tema propuesto en el contexto de la formación continua del profesorado, contribuciones de García (1992), Imbernón (2010, 2011), André (1999, 2015), Vaillant y Marcelo (2015), Gatti (2013), Gatti et al. (2019) y Nóvoa (2009). Los resultados mostraron que la educación continua es esencial para la calidad de la enseñanza. Sin embargo, el día de la capacitación, aunque los maestros informaron que estarían presentes, muchos no asistieron. Tal evento nos hace reflexionar que no es suficiente que el coordinador pedagógico del colegio brinde momentos de capacitación para su grupo de maestros, sino que es necesario que exista una asociación de colaboración dentro de las instituciones de enseñanza y una conciencia de la auto-capacitación de los maestros.

Palabras clave: Coordinación pedagógica. Formación continua del profesorado. Entrenamiento Centrado en la Escuela. 


\section{INTRODUÇÃO}

O tema que orientou o desenvolvimento desta pesquisa considera o papel do coordenador pedagógico nos espaços educacionais e a contribuição deste, para que organize e proporcione na instituição em que atua, momentos de formação para o corpo docente, na compreensão de que tais momentos, contribuem para que o professor reflita, organize e reorganize sua prática docente, já que ao compartilhar conhecimentos com outros profissionais da mesma instituição, poderão relatar e trocar experiências, valores e ideias, buscando a superação e alicerces suficientes para enfrentar os desafios encontrados no dia a dia em sala de aula, tendo como objetivo a qualificação da prática docente com foco na aprendizagem dos estudantes.

Sob esse olhar, Gatti (2013) observa que ao desenvolver ações pedagógicas que propiciem aprendizagens efetivas, os professores poderão contribuir para o desenvolvimento humano-social dos estudantes e essencialmente, para a construção de uma civilização. Além disso, a formação pode trazer ao professor uma maior motivação para continuar realizando o seu trabalho com empenho, dedicação e compromisso com seu ato de ensinar e educar.

Gatti (2013), ao mesmo tempo expõe que a preocupação com a educação escolar nos faz refletir sobre as relações pedagógicas intencionais, e consequentemente na relevância de profissionais bem formados dentro das novas configurações sociais, profissionais detentores de ideias e práticas educativas criadoras, ou seja, preparados para exercer à docência com consciência, conhecimentos e instrumentos.

Ressalta-se que, a formação continuada de professores tem sido foco de atenção de estudiosos da área educacional, destacando-se dentre outros os trabalhos de Imbernón (2010, 2011), André (1999, 2015), Garcia (1992), Vaillant e Marcelo (2015), Gatti (2013), Gatti et al. (2019) e Nóvoa (2009) que serviram de grande referência para a elaboração deste artigo. 
Desse modo, a presente pesquisa foi realizada em um Colégio da rede privada de ensino, localizado em uma cidade do interior do Vale do Itajaí (SC) e teve por objetivo, analisar o papel do coordenador pedagógico na formação continuada de professores centrada na escola, na respectiva instituição de ensino. Para tal, foi realizado o acompanhamento com a coordenadora pedagógica da instituição durante três dias. Posteriormente, durante dois dias foi aplicado um questionário semiestruturado com todos os profissionais que atuam em sala de aula no período matutino e vespertino do $1^{\circ}$ ao $4^{\circ}$ ano do Ensino Fundamental I com vistas a identificar o interesse dos mesmos e promover na escola um período de formação docente. A formação para compartilhar experiências e conhecimento com o grupo de professores aconteceu no sétimo dia do estágio supervisionado em Gestão Escolar. Corroborando com Gatti et al. (2019, p. 150) "o coordenador pedagógico tem o papel de formador e age como um mediador desse processo".

A seguir, será apresentado o percurso metodológico utilizado no desenvolvimento desta pesquisa. Posteriormente, será elucidado a respeito da formação continuada de professores no Brasil, seguido de uma reflexão sobre a qualidade de ensino no país e a formação de professores. Em seguida, apresenta-se a análise dos resultados da pesquisa, seguido das considerações finais.

\section{PERCURSO METODOLÓGICO}

Esta pesquisa configura-se por ser qualitativa, e os procedimentos metodológicos que a nortearam definem-na como uma pesquisa de campo do ponto de vista dos objetivos da pesquisa. Bogdan e Biklen (1994, p.48) observam que "na pesquisa qualitativa os investigadores frequentam os locais de estudo porque se preocupam com o contexto. Entendem que as ações podem ser melhor compreendidas quando são observadas no seu ambiente habitual de ocorrência". 
Ainda com relação a este tipo de pesquisa, Teixeira (2007) expõe que o investigador qualitativo procura reduzir a distância entre a teoria e os dados, entre o contexto e a ação, empregando a lógica da análise fenomenológica, isto é, da apreensão dos fenômenos pela descrição e interpretação. Os conhecimentos e experiências pessoais do pesquisador são informações importantes na análise e compreensão dos fenômenos estudados.

Conforme já destacado, a presente pesquisa surgiu do Estágio Supervisionado em Gestão Escolar do curso de Pedagogia e para atender ao objetivo proposto, houve durante três dias no período matutino o acompanhamento junto à coordenadora pedagógica da instituição para observar a função exercida pela mesma. Além disso, nesse acompanhamento, a coordenadora pedagógica mostrou à estagiária o Projeto Político Pedagógico (PPP) da referida instituição de ensino. Posteriormente, durante dois dias foi aplicado um breve questionário semiestruturado contendo quatro perguntas abertas e fechadas com os professores do $1^{\circ}$ ao $4^{\circ}$ ano do Ensino Fundamental I com vistas a identificar o interesse dos mesmos para que, em seguida, no sexto dia de estágio houvesse o planejamento da formação docente pela estagiária, para que então, no sétimo dia, pudesse ser desenvolvido um período de formação docente aos professores centrada na escola.

Ao todo, foram aplicados 13 questionários semiestruturados com todos os profissionais que atuam em sala de aula no período matutino e vespertino do $1^{\circ}$ ao $4^{\circ}$ ano, desses, três eram auxiliares de classe; dois estudantes de Pedagogia; um formado em licenciatura em Educação Física, mas atuante como auxiliar de classe; e sete já eram professores licenciados no curso de Pedagogia.

Após a tabulação dos dados do questionário semiestruturado, que poderá ser evidenciado mais adiante na análise, foi preparado um período de formação para os professores do Ensino Fundamental I, com dois temas que mais foram elencados pelos professores participantes da pesquisa, atendendo a necessidade e o interesse dos mesmos, pois as pesquisadoras 
compreendem que a construção de um projeto de formação para professores necessita estar relacionado com o contexto escolar, partindo das situações que transcorrem a dinâmica da escola e da sala de aula, valorizando os saberes dos professores, proporcionando a troca de experiência e desenvolvendo atividades relacionadas ao projeto políticopedagógico da escola (NORONHA; SARTORI; SOUZA, 2010).

\section{A FORMAÇÃO CONTINUADA DE PROFESSORES NO BRASIL}

Imbernón (2010) em seu livro "formação continuada de professores" observa que em todos os países e em todos os discursos, a formação continuada começa a ser assumida como fundamental, a fim de obter sucesso nas reformas educacionais. No entanto, de forma paradoxal, há muita formação e pouca mudança. Talvez seja porque ainda exista uma predominância de formações com predomínio de uma teoria descontextualizada com a necessidade real dos professores, uma formação transmissora e uniforme que não leva em consideração os problemas práticos e reais fundamentada em um professor ideal que não existe. No entanto, esse discurso já é antigo e vem acontecendo desde meados dos anos 80. Porém, atualmente, muitos cursos de formação continuam sendo ministrados, mas é evidente que há pouca inovação desde então.

Além disso, há o reconhecimento de que a formação inicial do docente exibe lacunas e que o contexto escolar é permeado por situações complexas ordenando que este profissional busque, através de um processo de formação continuada, formas e mecanismos para melhoria da sua prática docente. Nesta perspectiva, ressalta-se a importância da equipe pedagógica da escola em articular e motivar as ações formativas para o desenvolvimento profissional não só dos docentes, mas também dos demais profissionais envolvidos no contexto escolar (SIQUEIRA; AGUIAR; COLARES; 2015). 
Contudo, para que a formação possibilite melhorias ao desenvolvimento docente dos professores, Imbernón (2011) enfatiza que esta, deve estar relacionada a tarefas de desenvolvimento curricular, planejamento de programas e em melhorias da instituição educativa e nelas implicar-se, tratando de resolver ocorrências problemáticas gerais do contexto escolar ou específicos relacionados ao ensino. Igualmente,

em decorrência disso, o professor precisa adquirir conhecimentos ou estratégias específicas (planejamento curricular, pesquisa sobre a docência, estratégias para formar grupos, resolução de problemas, relações com a comunidade, atividade sociocultural etc.). Tudo isso supõe a combinação de diferentes estratégias de formação e uma concepção do papel do professor nesse contexto, o que obviamente não pode ser feito sem o envolvimento concreto dos docentes (IMBERNÓN, 2011, p. 18).

André et al. (1999), ao realizar o estado da arte da Formação de Professores no Brasil, compendiaram o conhecimento sobre o tema, adotando como base a análise de dissertações e teses defendidas nos programas de pós-graduação na área de educação no Brasil, nos anos de 1990 a 1996, além de analisar artigos publicados em dez periódicos da área no período de 1990 e 1997 e pesquisas apresentadas nos Grupos de Trabalho de Formação de Professores da Associação Nacional de Pós-Graduação e Pesquisa em Educação (Anped), de 1992 a 1998. De acordo com Prado et al. (2019) este mapeamento do conhecimento referente à formação continuada de professores no Brasil corroborou com a crescente preocupação com a prática docente nos anos iniciais do Ensino Fundamental e identificou que, de modo geral, esta formação é

identificada como formação em serviço, enfatizando o papel do professor como profissional e estimulando-o a desenvolver novos meios de realizar seu trabalho pedagógico com base na reflexão sobre a própria prática (ANDRÉ et al. 1999, p. 308).

Mais recentemente, André (2015) observa uma tendência de formação continuada que vem se firmando na produção escrita recente, tanto no Brasil quanto no exterior, é a formação que considera a escola como o local por excelência da formação dos professores. Souza e Placco 
(2014), igualmente expõe que a formação "centrada na escola" tem a instituição de ensino como lócus de formação dos professores e que a mesma, apareceu na década de 1970 na OCDE (Organização para Cooperação e o Desenvolvimento Econômicos) para responder os questionamentos que eram feitos sobre a ineficácia da formação de professores. Na formação centrada na escola, os docentes decidem, em conjunto, o tipo de formação que desejam, planejam, executam e avaliam seu trabalho, constituindo equipes colaborativas nas escolas (ANDRÉ, 2015).

Nessa perspectiva, André (2015) observa que o desenvolvimento profissional não pode ficar restrito ao domínio individual e utilitário. Os programas de formação continuada devem ser delineados para mobilizar os docentes a trabalharem coletivamente, promovendo mudanças nas escolas que atendam cada vez melhor às necessidades dos estudantes. As tarefas de melhoria da escola precisam ser realizadas pelo coletivo, em um processo de interação, de trocas, de colaboração.

Cabe destacar, o papel do coordenador pedagógico nesse processo, que se torna fundamental nas instituições de ensino frente à formação continuada. Placco, Souza e Almeida (2012) expõe que são muitas as atribuições desses profissionais, definidas pelas legislações estaduais e/ou municipais, abarcando desde a liderança do projeto político-pedagógico (PPP) até funções administrativas de assessoria na direção, mas, sobretudo, atividades relativas ao funcionamento pedagógico da escola e de apoio aos professores, tais como: avaliação dos resultados dos estudantes, diagnóstico da situação de ensino e aprendizagem, supervisão e organização das ações pedagógicas do dia a dia, andamento do planejamento de aula, planejamento das avaliações, organização de conselhos de classe, organização das avaliações externas, material necessário para as aulas e reuniões pedagógicas, atendimento de pais, além da formação continuada dos professores. Diante de tantas funções, assumidas por esse profissional, sobra pouco ou nenhum tempo para sua função formadora de professores, que deveria ser priorizada (PLACCO; ALMEIDA; SOUZA, 2015). 
Neto e Silva (2019) realizaram um panorama das pesquisas sobre formação continuada de professores nas reuniões da Anped entre os anos de 2000 e 2018 e relataram que a categoria com maior quantidade de artigos publicados no período pesquisado foi "Experiências de Formação continuada de professores". São artigos que dialogam sobre os programas ou experiências alusivas à formação continuada de professores, sobre o desenvolvimento profissional, pesquisa colaborativa, comunidades de prática, formação à distância, serviço de tutoria.

Garcia (1992) ao dialogar sobre o conceito de formação de professores observa que ele não é unívoco, e que ao utilizar esse termo, assume-se determinadas posições epistemológicas, culturais e ideológicas, com relação ao ensino, ao professor e aos alunos. O autor defende que, ao mesmo tempo, um primeiro aspecto que deve ser ressaltado é a concepção de formação com um "continum", tal perspectiva não defende a formação inicial como acabada e sim, a formação por toda a vida, na qual concebe a definição de "desenvolvimento profissional dos professores" como um termo mais cabível para referir-se à formação contínua que perpassa a formação inicial. Gimeno (1990 apud GARCIA, 1992, p. 55) defende a necessidade de estabelecer o aperfeiçoamento dos professores como "um modelo de desenvolvimento profissional e pessoal, evolutivo e continuado".

Ao mesmo tempo, a formação contínua deve propiciar ainda uma reflexão na ação docente. Sob essa perspectiva, Kemmis (1987 apud GARCIA, 1992), expõe que as escolas não podem mudar sem o compromisso assumido pelos professores e que eles não podem mudar sem 0 compromisso das instituições em que trabalham, que ambos são interdependentes e interativos no processo de reforma educacional e que a educação só poderá reformar-se transformando as práticas que a constituem.

Imbernón (2010), salienta que qualquer inovação que se pretenda realizar mediante a formação não pode negligenciar as relações laborais dos professores com a administração educativa em que atua, nem a adequação dos mesmos dentro do sistema educacional em função da 
idade, da especialidade, das expectativas de progresso no trabalho ou da formação docente. Para o autor, as relações trabalhistas devem ser revisadas e não apenas o salário dos docentes, pois em muitos países latinoamericanos ainda há um número significativo de professores contratados que não possuem o mínimo de condições para seu desenvolvimento profissional docente, falta-lhes formação ou titulação e condições de chegarem até as escolas, que por vezes fica muito longe de seu local de trabalho. Nesse sentido, falar de formação continuada e desenvolvimento profissional dos professores nessas circunstâncias parece mais uma tentativa de aparentar uma adequação a certas reformistas do que considerar a realidade de uma mudança da educação e dos docentes.

Vaillant e Marcelo (2015) contribuem com a discussão observando que, apesar da importância que o desenvolvimento profissional dos professores tem, tanto para o professor quanto para a qualidade do ensino, a tradição tem assinalado um tipo de desenvolvimento profissional marcado pela expulsão das necessidades dos professores, estudantes e escolas, sem levar em conta as etapas do desenvolvimento profissional docente. A maior parte das atividades de educação continuada para professores são eventos esporádicos, e não experiências evolutivas de aprendizado. Essas atividades tendem a ser intelectualmente superficiais, desconexas dos temas profundos do currículo e da aprendizagem dos alunos e na maioria das vezes são fragmentadas e não cumulativas. Os temas são determinados por outras pessoas que não os professores e não levam em consideração o que eles sabem sobre como aprender (VAILLANT; MARCELO, 2015).

Com relação às etapas da formação docente, os autores Vaillant e Marcelo (2015) nos trazem importantes contribuições e as denominam de "A, $B, C$ e D". A seguir, apresenta-se brevemente o que significa cada período de acordo com a compreensão dos autores.

Etapa A - de Antecedentes: Esse período é caracterizado pela etapa prévia do ofício de ensinar. Os aspirantes a docentes trazem consigo uma série de crenças e imagens baseadas em suas próprias experiências que influenciam a forma como enfrentam a complexa tarefa de dar aula. A 
socialização do futuro docente é resultado de um grupo de fatores, dentre os quais a experiência escolar da primeira infância, a influência de diretores e supervisores e o peso dos agentes sociais não profissionais, como amigos e familiares, possuem importância. Contudo, os estudantes que querem ser professores não têm consciência do que sabem, nem de como e porquê conhecem. Além disso, dificilmente os professores os ensinam a refletir sobre suas crenças. Por isso, geralmente os formadores fracassam na hora de influir concepções prévias dos candidatos à docência, pois sua linguagem está desconectada da experiência dos próprios aspirantes (VAILLANT; MARCELO, 2015).

Etapa B - de Base: Esse período é caracterizado pela fase de formação inicial do docente. A formação inicial do docente ao longo da história vem sendo exercida por instituições específicas, por um grupo especializado e mediante um currículo que institui a sequência e o conteúdo instrucional do programa formativo. A formação inicial docente como instituição exerce basicamente três funções: em primeiro lugar, de preparação dos futuros docentes, de modo que garanta desempenho adequado na aula. Em segundo lugar, a instituição formativa tem a função de certificação e consentimento para poder desempenhar a profissão docente, e em terceiro lugar, a instituição de formação do docente cumpre a função de socialização e reprodução da cultura dominante (VAILLANT; MARCELO, 2015).

Ełapa C - de Começo: Essa fase é caracterizada pelos primeiros anos de vida profissional do professor. Nessa etapa importante de aprender a ensinar, os docentes formados ingressam nas escolas como docentes iniciantes. Essa fase inclui medidas de apoio e supervisão, além de uma avaliação formal para certificar a obtenção de habilidades sem as quais os docentes não poderiam exercer a profissão. Durante esse período, os professores não são totalmente habilitados e frequentemente são considerados candidatos ou estagiários (VAILLANT; MARCELO, 2015).

Ełapa D - de Desenvolvimento: Essa fase é caracterizada pelo desenvolvimento profissional contínuo do docente. Muitos termos têm sido 
utilizados para falar de desenvolvimento profissional, como formação contínua, formação em serviço, ou formação permanente. Desse modo, o conceito de desenvolvimento tem uma conotação de evolução e continuidade, que ultrapassa a tradicional justaposição entre formação inicial e aperfeiçoamento dos docentes. Estamos longe da época em que se pensava que os conhecimentos obtidos na formação inicial de professores, juntamente com o valor da experiência como fonte de aprendizado na prática, poderiam ser suficientes para solidificar $\bigcirc$ trabalho docente (VAILLANT; MARCELO, 2015).

Nesta pesquisa, justamente enfatiza-se a última etapa do desenvolvimento profissional docente exposto pelos autores citados acima, é a etapa "D" marcada pelo desenvolvimento profissional dos professores, pela formação contínua.

\section{QUALIDADE DE ENSINO NO BRASIL E A FORMAÇÃO DE PROFESSORES}

A partir da Constituição Federal de 1988, a educação conquista novos direitos no Brasil, O Ensino Fundamental passa a ser obrigatório, universalmente atendendo à crianças e adolescentes entre 7 e 14 anos de idade. Maiores de 15 anos também possuem o direito, mas só o usufruem se assim exigirem. Até então, a gratuidade no país só tinha vigência para o ensino obrigatório de 8 anos. De acordo com o Art. 205. A educação, passa a ser um direito de todos e dever do Estado e da família, promovida e incentivada com a colaboração da sociedade, tendo em vista o desenvolvimento da pessoa, seu preparo para o exercício da cidadania e sua qualificação para o trabalho. Garantindo dessa forma, não só o acesso, mas o direito a permanência dos cidadãos na escola (BRASIL, 1988). A gratuidade passa a valer também para o Ensino Médio e Superior. O Ensino Médio é constitucionalizado em 1988, no entanto, perde sua obrigatoriedade na emenda constitucional 14/96, que cria o fundo de Manutenção do Ensino Fundamental, e reposto em lei ordinária no mesmo ano. Com a Lei de Diretrizes e Bases da Educação Nacional (LDB) 9.394/96, a 
Educação Básica passa a ser obrigatória abrangendo a Educação Infantil, o Ensino Fundamental, o Ensino Médio e a Educação de Jovens e Adultos (BRASIL, 1996).

Dessa forma, com a obrigatoriedade do ensino e a disseminação do acesso dos alunos nas escolas, também se disseminou o discurso sobre uma "educação de qualidade". Enguita (1994, p.95) observa que, "se existe hoje uma palavra em moda no mundo da educação, essa palavra é sem dúvida, "qualidade". A encontramos principalmente empregada ao relatar que "necessitamos melhorar a qualidade da educação" ou ao expor que "a baixa qualidade da educação compromete o país", o uso desses termos denota um apontamento positivo ou negativo, entretanto, educação de qualidade para todos e qualidade da educação ainda é um desafio no Brasil (GUSMÃO, 2013).

Gentili (2007), observa que ao iniciar o discurso sobre o que seria uma educação de qualidade, este sobressaiu-se ao discurso da democratização do ensino, instalando-se o discurso hegemônico da qualidade e que apesar de a democracia ser sempre uma conquista política das maiorias, as condições em que as democracias concretas tendem a se constituir podem refletir situações estruturais de profunda derrota social (GENTILI, 2007). O autor supracitado, observa ainda que no campo educativo, a euforia democratizadora do primeiro período pós-ditatorial, foi como se tivessem sido anuladas todas as referências necessárias à democratização dos sistemas de ensino. Em uma década, a democratização da educação deixou de ser a engrenagem que deveria nortear as políticas públicas educacionais para constituir-se como um tema ausente e silenciado no cenário político latino-americano. Não que ela tenha desaparecido no campo intelectual, mas a intencionalidade da política foi se assemelhando cada vez mais as classes dominantes, assumindo o discurso neoconservador e neoliberal. (GENTILI, 2007).

Dessa forma, com a obrigatoriedade de ensino pela Constituição Federal de 1988, a ampliação da escolarização ficou acessível a um maior número de pessoas, o que antes era restrito apenas à classe elitizada da 
população. O processo consistiu assim em colocar vinho novo em tonéis velhos, em acionar todos a um ensino que não havia sido configurado pensado na sociedade como um todo, mas em uma parte reduzida da mesma (ENGUITA, 1994).

Os autores Oliveira e Araujo (2005) expõem que o primeiro indicador de qualidade acionado na cultura escolar brasileira foi condicionado pela oferta limitada, e um dos seus principais efeitos foi a política de expansão da oferta pelo aumento do número de escolas, por outro, a ampliação das oportunidades de escolarização da população provocou obstáculos relativos à continuação dos estudos desses novos usuários da escola pública, visto que não tinham as mesmas experiências culturais dos grupos que tinham acesso à escola anteriormente, e esta não se reestruturou para receber essa nova população.

Dessa forma, os impedimentos à democratização do ensino foram expandindo-se do acesso para a permanência nas instituições escolares e a qualidade em educação, também pode ser compreendida como uma estratégia mercantilista e competitiva. De acordo com Gentili (2007) a questão é tão simples como evidente, a qualidade alterou-se principalmente a partir da crise do regime de acumulação fordista em uma nova tática competitiva de acordo com um mercado cada vez mais diversificado.

Nesse contexto, fica cada vez mais impreciso definir o conceito de "qualidade", visto as características polissêmicas subjetivas desse termo, podendo remetê-la as diferentes estruturas, sujeitos e políticas que constituem e perpassam pela instituição denominada escola. Igualmente, muitos educadores se questionam sobre o que de fato seria uma educação de qualidade e buscam métodos diversificados para aplicar em suas aulas, com o objetivo de torná-las mais atrativas para seus alunos, e propiciar uma "educação de qualidade".

Imbernón (2011) igualmente salienta que o consenso sobre seu significado nem existe num único modelo, pois ele depende da concepção de formação e ensino que se tem. No entanto, durante muito tempo esse conceito foi interpretado como absoluto, próximo às dimensões de inato e 
de atributo de um produto. Nos últimos tempos, porém, a qualidade em educação vem sendo analisada a partir da consciência do aluno, de como ele a percebe, mas diferentemente de algumas posturas mais conservadoras que introduzem indicadores de desempenho para mensurar a qualidade em educação, consequentemente ela vem sendo vista como uma tendência, uma trajetória, como um processo de construção contínua.

Araújo (2011) observa que, ao longo da história da educação, os esforços para a melhoria da qualidade de ensino vêm sendo discutidas e dependem de cada época, contexto histórico e social, já que cada momento privilegia determinada metodologia de ensino, ou o domínio dos conteúdos pelos professores ou então, o currículo escolar. Entretanto, as ações isoladas, configuram-se como paliativas para abarcar os problemas da educação enfrentados no país.

Assim compreendida, embora em toda sua polissemia, a definição de qualidade, pressupõe por fim, reconhecer os sujeitos enquanto principais responsáveis pela construção de uma educação que se define por qualidade. Isso passa por "entender a escola como espaço de construção de significados e sentidos, pela construção de uma educação que valorize a ética pública, a participação, a responsabilização social" (ARAÚJO, 2011, p. 176). Por conseguinte, as pesquisadoras deste trabalho compreendem que uma das maneiras de contribuir para uma educação de qualidade é por meio da formação continuada de professores, pois, para que novas ideias surjam e contribuam com a prática pedagógica do professor, o mesmo precisa estar disposto a participar de momentos de formação continuada, se apropriando de novos conhecimentos, utilizando novas práticas em sala de aula, sem se ater exclusivamente em uma única "solução", já que não "há soluções mágicas" para a questão da qualidade em educação.

Nas instituições escolares, cabe destacar, por certo, o papel do coordenador pedagógico frente aos momentos de formação continuada dos professores, já que ele, conforme mencionado por Orsolon (2006), por meio de articulações externas que realiza com os professores num movimento de interação permeada por valores, crenças e atitudes e, por 
meio da articulação interna, que sua ação desencadeia nos professores, na medida em que mobiliza suas dimensões políticas e sociais reveladas em sua prática, articula o trabalho coletivo, observando e congregando as necessidades dos que atuam na escola. Nesse contexto, é o coordenador que irá mediar tais momentos, nos quais o saber fazer, o saber ser e o saber agir do professor estão presentes.

Do mesmo modo, Orsolon (2006) observa que ao conhecer o contexto e as necessidades dos professores, o coordenador poderá criar condições para questionar as práticas vivenciadas por eles, disponibilizando recursos para poder transformar essa prática com a introdução de uma proposta curricular inovadora baseada em uma formação continuada voltada para as necessidades dos professores. A aprendizagem mediante a vivência desse saber-fazer na escola viabilizaria a interdisciplinaridade no campo do conhecimento e admitiria o questionamento das práticas docentes vigentes, no sentido de transformá-las.

Desse modo, as pesquisadoras compreendem e corroboram com os autores já mencionados e com Noronha, Sartori e Souza (2010) quando expõem que a formação continuada não deve ser desenvolvida apenas a partir de exigências legais, unicamente pela necessidade de progressão profissional ou por interesses definidos de "cima para baixo", mas precisa surgir do desejo explícito dos professores e profissionais da escola, como períodos significativos para a constituição da identidade profissional.

Lück (2006) observa que é necessário haver modificações sensíveis na organização e orientação da educação no Brasil, a fim de promover no país educação em nível de qualidade tal que este possa participar ativamente do processo de globalização da economia e internacionalização cultural, a fim de que a população brasileira não fique à margem do desenvolvimento, como também possa colaborar para o mesmo e usufruir desse movimento geral.

Para finalizar esta reflexão, Imbernón (2011) salienta que exigir qualidade da formação e do ensino é uma questão ética e de 
responsabilidade social para evitar que se caia na falácia. Temos de buscar a qualidade, mas sabendo que sua riqueza já se encontra no caminho.

\section{ANÁLISE DOS DADOS}

Durante os primeiros três dias de planos de ação houve o acompanhamento com a coordenadora pedagógica, no qual foi possível realizar uma análise de todo o Projeto Político Pedagógico do colégio (PPP), bem como, todos os documentos, normas e regimentos internos da instituição.

Ao analisar O PPP da respectiva instituição de ensino, a estagiária indagou a coordenadora pedagógica sobre a utilização do mesmo pelas professoras na realização do planejamento e esta observou que:

as professoras do Colégio possuem acesso a este documento, e quando necessário elas podem utilizá-lo. No entanto, para o planejamento, ele não é manuseado rotineiramente, pois elas possuem todos os materiais pedagógicos em sala de aula, como livros, encaminhamento, plano de atividades, que as orientam para os conteúdos e critérios estabelecidos pelo Colégio (Coordenadora Pedagógica, grifos nosso).

Ao analisar os materiais pedagógicos que a coordenadora dispõe como referência para o acompanhamento do planejamento realizado pelas docentes, foi possível perceber que o PPP da referida instituição de ensino encontra-se diretamente atrelado aos materiais pedagógicos que são encaminhados às professoras para a realização das atividades pedagógicas com os estudantes. Igualmente, Ramos (2016) observa que o PPP precisa estar pautado nas práticas pedagógicas dos professores e ter bem definido o que a instituição pretende alcançar com os alunos, quais são os objetivos, as dificuldades, como superá-las e quais estratégias pedagógicas serão utilizadas para que os objetivos propostos no PPP sejam alcançados.

De acordo com o PPP da instituição de ensino observada, todo o corpo docente e administrativo apresenta habilitação específica descrita na 
legislação vigente, para a sua atividade pedagógica. O programa de Educação Corporativa (PEC) desenvolvido pela instituição, viabiliza a educação continuada dos professores durante a jornada laboral e os encontros presenciais oportunizam o entrosamento entre eles, propõem novas ideias, momentos de estudo e reflexão, dão oportunidade de expressão e visam à capacitação profissional. Ainda de acordo com o PPP, são promovidos encontros entre os docentes e demais funcionários para trocas de experiências e palestras com profissionais reconhecidos pelas pesquisas desenvolvidas. Do mesmo modo, como parte da dimensão de aperfeiçoamento profissional, é disponibilizado aos professores um acervo de livros, revistas, reportagens de jornais, vídeos e outros, na Biblioteca do Colégio e Midiateca, no Centro de Estudos e Pesquisa.

A coordenadora pedagógica também relatou à estagiária, que

as professoras realizam um plano de ensino semanal e fazem em conjunto, de acordo com as respectivas séries em que lecionam, baseando-se no cronograma estabelecido pelo plano curricular e nos objetivos por área. Todas as professoras possuem um livro denominado de "Encaminhamento Pedagógico" de acordo com a turma em que lecionam, outro livro denominado "Planejamento de Atividades", e outro livro "Plano Curricular". As professoras se baseiam nesses materiais para realizar o planejamento das aulas, no entanto o planejamento pode ser alterado se necessário, sendo incorporado mais ideias e novidades, de acordo com o interesse dos alunos (Coordenadora Pedagógica, grifos nosso).

O trabalho e o planejamento em conjunto são vistos como positivo e a coordenadora pedagógica recebe semanalmente o planejamento dos professores e os orienta, sempre que necessário. Nóvoa (2009), do mesmo modo, observa que a complexidade do trabalho escolar demanda um aprofundamento das equipes pedagógicas e salienta que a competência coletiva é mais que o somatório das competências individuais, sendo necessário integrar na cultura docente um conjunto de modos coletivos de produção e de regulação do trabalho do professor.

Posteriormente, durante dois dias houve a aplicação de um questionário com os professores do $1^{\circ}$ ao $4^{\circ}$ ano do Ensino Fundamental I, para fazer uma sondagem, acerca dos interesses dos mesmos, para que, em 
seguida, no sexto dia de estágio houvesse o planejamento da formação docente pela estagiária, para que então, no sétimo dia, fosse desenvolvido um período de formação docente aos professores centrada na escola. Torna-se importante salientar que, com vistas a atender o maior número de profissionais da escola e conforme acordado com a coordenadora pedagógica, bem como, com os professores participantes da pesquisa, a formação foi realizada no período noturno.

Com relação à formação centrada na escola, Imbernón (2011) expõe que ela envolve todas as estratégias empregadas conjuntamente pelos professores e formadores de modo a responder às necessidades definidas da escola e elevar a qualidade do ensino e aprendizagem dos estudantes. Igualmente, quando se fala em formação centrada na escola, compreende-se que ela se transforma em lugar de formação prioritária diante de outras ações formativas. Ela é mais que uma simples mudança de lugar da formação. Imbernón (2011, p. 86-87) observa ainda que,

a instituição educacional é vista como "nicho ecológico para o desenvolvimento e a formação". O professor é sujeito e não objeto de formação. Parte da premissa de que o profissional de educação também possui uma epistemologia prática, possui um conhecimento e um quadro teórico construído a partir de sua prática. Por isso é necessário um modelo de aprendizagem cujas metas sejam dirigir-se a si mesmo e orientar-se para a capacitação para a autonomia e cujas características principais sejam: criação de atitudes de valorização e respeito; presença de um currículo de formação articulado em torno das necessidades e aspirações dos participantes; estabelecimento de relações de estímulo e questionamento mútuo.

Com os dados obtidos por meio do questionário semiestruturado, foi possivel constatar que quando questionados, todos os professores consideram importante a formação continuada para o aprimoramento do fazer docente. Imbernón (2011) ao dialogar sobre a formação permanente dos professores observa que esta, deveria fazer com que os professores se tornassem menos individualistas e pudessem trabalhar numa perspectiva colaborativa com os outros profissionais, superando o ponto de vista estritamente individual, aplicado ao conhecimento profissional, em que a 
colaboração entre os companheiros se faz ausente. Essa colaboração que o autor se refere, diz respeito à construção de um conhecimento profissional coletivo e exige que se desenvolvam nessa etapa instrumentos intelectuais para facilitar as capacidades reflexivas coletivas sobre a própria prática docente.

Ao terem a possibilidade de escolher o que gostariam de vivenciar em um momento de formação continuada no Colégio, vislumbrou-se a possibilidade de discorrer sobre o tema com os professores, tendo a finalidade de compartilhar experiências na construção de novos saberes e aprimoramento da prática docente. Gatti et al. $(2019$, p. 187) observa que,

é importante promover oportunidades para que os professores testem seus conhecimentos teóricos, exigindo, que em alguns momentos, seus princípios sejam explicitados e revistos e que diferentes saberes sejam mobilizados para que haja uma profunda compreensão da complexidade da atividade docente.

Ao preencherem o questionário, uma das perguntas questionava se os períodos de formação oferecidos pelo colégio eram possiveis para atender a todas as necessidades e, seis professores responderam que "seriam necessários mais momentos de formação continuada". Quatro professores participantes, responderam que o período de formação disponibilizado pelo Colégio "atende parcialmente as necessidades" e um desses complementou expondo "que seriam necessários mais momentos de formação continuada". Dois professores expuseram que "sim", o colégio oferece períodos de formação suficientes para atender as necessidades dos professores, mas um desses complementou expondo que "seriam necessários mais momentos de formação continuada".

Diante desses relatos, fica evidente que dos 13 professores, apenas dois relataram que o Colégio oferecia períodos de formação suficientes e desses dois, um se contradisse, pois, complementou relatando que "seriam necessários mais momentos de formação continuada". Gatti et al, (2019, p. 190) ressalta que "professores que aprendem a refletir junto com seus pares colaboram reciprocamente para o desenvolvimento profissional de cada 
um e enriquecem-se mutuamente", nesse sentido, os momentos de formação continuada contribuem para o fortalecimento do campo profissional e o ambiente de trabalho docente.

Ao responderem sobre quais seriam as maiores necessidades encontradas no dia a dia em sala de aula, seis professores afirmaram que "trabalhar com os diferentes ritmos de aprendizagem existentes". Outro professor relatou "resolução de conflitos entre os alunos". Dois professores assinalaram mais de uma opção e relataram: "resolução de conflitos entre os alunos e trabalhar com os diferentes ritmos de aprendizagem existentes". Outro professor também assinalou mais de uma opção "trabalhar com os diferentes ritmos de aprendizagem existentes, e o ensino da matemática (ciência exata e abstrata), e a dificuldade que alguns alunos apresentam diante desta disciplina". E, dois professores relataram ainda "lidar com alunos indisciplinados (a falta de respeito diante o professor)".

Campos e Caron (2016) descrevem que a socialização dos professores nos momentos de formação permite que os saberes compartilhados sejam gerados de forma crítica e reflexiva, relacionados aos desafios de aprendizagem que o docente se depara em sala de aula, pois o processo formativo realizado no coletivo desperta nos professores o compromisso de promover uma educação centrada no avanço do processo educativo dos estudantes.

Nóvoa (2009) e Imbernón (2011) igualmente defendem que, a formação de professores deve valorizar o trabalho em equipe no ambiente escolar e que a escola deve ser vista como um lugar da formação de professores, constituída em um espaço de partilha das práticas pedagógicas e de reflexão sobre o trabalho docente. Imbernón (2011, p. 90-91) expõe ainda que "a formação centrada na escola transforma a instituição educacional em um local de formação prioritário em relação a outras ações formativas".

Por fim, quando questionados sobre um dos temas que eles gostariam que fosse explorado em uma formação continuada, alguns professores 
assinalaram mais de uma opção, conforme pode ser observado no quadro abaixo:

Quadro 01: Temas de interesse dos Professores para Formação Continuada

\begin{tabular}{|c|c|}
\hline $\begin{array}{c}\text { Temas de interesse dos Professores para } \\
\text { Formação Continuada }\end{array}$ & Interesse demonstrado pelos Professores \\
\hline $\begin{array}{c}\text { Pragmatismo, uma Aprendizagem para o } \\
\text { Futuro. }\end{array}$ & 04 Professores \\
\hline $\begin{array}{l}\text { Importância da Afetividade para } \\
\text { que ocorra a Aprendizagem }\end{array}$ & 05 Professores \\
\hline $\begin{array}{l}\text { Utilizando os Jogos e Ensinando a } \\
\text { Matemática no Ensino Fundamental I - } \\
\text { Contribuições de Jean Piaget. }\end{array}$ & 03 Professores \\
\hline $\begin{array}{c}\text { Abordagem das Múltiplas } \\
\text { Inteligências - Howard Gardner. }\end{array}$ & 04 Professores \\
\hline $\begin{array}{l}\text { Contando Histórias no Ensino } \\
\text { Fundamental - Importância da Literatura. }\end{array}$ & Nenhum Professor escolheu essa opção \\
\hline
\end{tabular}

Fonte: Elaborado pelas pesquisadoras (2020).

Analisando os resultados obtidos diante do questionário semiestruturado, o tema escolhido para um período de formação continuada e reflexão juntamente com os professores foi: "A Importância da Afetividade para que ocorra a Aprendizagem". No primeiro momento, seria elencado apenas um tema, no entanto, em conversa com a coordenadora do Colégio que atua no segmento observado (Educação Infantil e Anos Iniciais), ficou acordado que seriam realizados dois momentos de formação e de partilha com os demais docentes durante uma noite, abordando os seguintes temas: "A Importância da Afetividade para que ocorra a Aprendizagem" e "Utilizando os Jogos e Ensinando a Matemática no Ensino Fundamental I - Contribuições de Jean Piaget". A escolha pela segunda opção justifica-se pela estagiária ter realizado seus estágios anteriores sobre esse tema e a coordenadora pedagógica da escola, conhecendo o trabalho realizado pela mesma, achou pertinente também dialogar com os professores sobre ele, além disso, ressalta-se que três professores o elencaram no questionário.

Ao possibilitar que os professores se sentissem à vontade para escolher um dos temas que mais the interessassem para posteriormente, compartilhar seus saberes com os demais profissionais, por meio de uma formação 
centrada na escola mediada pela estagiária que, naquele momento, estava por meio do Estágio Supervisionado em Gestão Escolar do curso de licenciatura em Pedagogia, vivenciando o papel de coordenadora pedagógica, demonstra o que Imbernón (2011) pontua, que é justamente importante a presença de um currículo de formação articulado em torno das necessidades e aspirações dos participantes, no qual há o estabelecimento de relações entre os pares e o questionamento mútuo.

Definidos os temas que seriam discutidos no momento da formação, foi entregue com alguns dias de antecedência um convite impresso para cada professor que participou do questionário semiestruturado e contribuiu com a escolha do tema. No momento da entrega do convite, todos os professores relataram que estariam presentes no dia da formação para compartilhar conhecimentos.

Após uma semana da entrega do convite aos professores, conforme a data combinada com ambos, esteve presente na formação: a psicopedagoga do Colégio, quatro professores, dos treze que responderam o questionário semiestruturado, e alguns familiares que atuam na área da educação que também foram convidados para participar deste momento. Importante expor ainda, que além dos professores que participaram da pesquisa, os professores que atuam na Educação Infantil também foram convidados a estarem presentes.

Os professores participantes que não puderam comparecer, posteriormente relataram a estagiária que "não poderiam estar presentes", justificando compromissos e motivos pessoais. A estagiária expõe que, compreende tal acontecimento, visto que a formação foi realizada fora do horário de trabalho dos professores. Contudo, durante o horário de aula, no período matutino e vespertino a formação não poderia ser realizada, pois os professores estavam lecionando. No entanto, os professores estavam cientes do horário com uma semana de antecedência e inicialmente haviam exposto que estariam presentes no dia programado pela estagiária.

A falta de comprometimento por assim dizer, de alguns profissionais demonstra a carência de uma cultura de formação de professores, como 
observa Nóvoa (2009, p. 44) "construída dentro da profissão, isto é, baseada numa combinação complexa de contributos científicos, pedagógicos e técnicos, mas que tem como âncora os próprios professores, sobretudo os professores mais experientes e reconhecidos".

Ao término da formação, os quatro professores presentes expuseram seus agradecimentos e demonstraram reconhecer a importância, de momentos como esse para refletir sobre a prática docente. A seguir, poderá ser visualizada a fala de alguns professores que estiveram presentes durante a noite de formação continuada no Colégio.

"Foi muito bom, eu até me senti mais animada, motivada! É bom às vezes ganhar um "chacoalham", porque muitas vezes no dia a dia, a gente acaba fazendo coisas na correria e não se dá conta, não para pra refletir, então momentos como esse são importantes para o professor parar, pensar e ver sua prática docente" (Professor 01, grifos nosso).

Outro professor que estava presente demonstrou concordar com o Professor 01 e relatou: "Porque nós que estamos aqui, acreditamos na educação, porque se não nós não estaríamos aqui, é porque a gente gosta do que faz!" (Professor 02, grifos nosso).

Ficou evidente que os professores demonstraram sentir-se instigados a realizarem esse movimento no Colégio, reunindo-se para dialogar, estudar e refletir uns com os outros, durante um período estabelecido por eles, para um momento de estudo e formação continuada. Nesse diálogo, um professor empolgado afirmou: "Uma vez por semana, talvez não daria, mas pelo menos uma vez por mês, poderíamos combinar, poderíamos discutir um tema, ler um livro, porque isso faz bem, motiva a gente, inspira" (Professor 03, grifos nosso).

Diante dessa fala, os Professores 01, 02 e 04 concordaram, relatando que "Quando vamos pra Blumenau no Colégio de lá4, os professores se reúnem parece que uma vez por semana, mas em horário de aula, no contraturno" (grifos nosso).

\footnotetext{
${ }^{4}$ Será preservado o nome do Colégio, pois o Colégio em que foi realizada a pesquisa está vinculado a uma metodologia de ensino seguida por demais Colégios da rede privada de Ensino em todo o país.
} 
Diante do exposto pelos professores presentes no momento de formação, foi possível observar o quanto momentos como esse enriquecem, valorizam e motivam o papel do professor dentro das instituições de ensino. Nesse sentido, Imbernón (2011, p. 91 ) expõe que

\begin{abstract}
na formação centrada na escola, a formação de professores converte-se em um processo de autodeterminação baseado no diálogo, na medida em que se implanta um tipo de compreensão compartilhada pelos participantes, sobre as tarefas profissionais e os meios para melhorá-las, e não um conjunto de papéis e funções que são aprimorados mediante normas e regras técnicas.
\end{abstract}

Diante dos relatos dos professores, foi possível perceber que os professores se demonstraram motivados a buscar mais aprofundamento e conhecimento acerca das teorias que permeiam a prática docente. É visivel que esse movimento de encontros para estudos que eles relataram, irá acontecer em determinado momento. Com certeza, seria muito produtivo e importante para a reflexão docente de cada professor e para o constante aperfeiçoamento e crescimento profissional docente.

\title{
CONSIDERAÇÕES FINAIS
}

O objetivo geral desta pesquisa foi analisar o papel do coordenador pedagógico na formação continuada de professores na respectiva instituição de ensino, por meio da observação e do acompanhamento da rotina de uma coordenadora pedagógica que atua no segmento da Educação Infantil e dos Anos Iniciais. Reitera-se, que a pesquisa teve como foco, a importância da formação continuada centrada na escola para os professores, ciente de que um dos papéis do coordenador pedagógico é proporcionar ao seu corpo docente momentos de estudo, reflexão e troca de saberes quanto à prática docente em sala de aula, bem como, compartilhar conhecimentos teóricos que norteiam essa prática.

Diante da análise dos dados e de toda a reflexão teórica feita até o presente momento, fica-nos a ponderação de que, não basta apenas o coordenador pedagógico propiciar momentos de formação para seu grupo 
de professores, mas é necessário que haja uma parceria colaborativa dentro das instituições de ensino.

As pesquisadoras consideram desse modo, que é necessário que cada profissional se conscientize de fato, do quanto à formação continuada é importante para o aprimoramento do fazer docente, da reflexão da prática, da troca de conhecimentos e experiências que cada professor traz e acima de tudo, da importância de valorizar a troca de conhecimentos com os demais profissionais que dividem o mesmo ambiente de trabalho, considerando, como observa Veiga (2007) que na atividade docente, ainda que pensada e planejada, surgem situações imprevistas e inusitadas, que demandam reflexão sobre a prática, intervenções e mudanças, a capacidade de questionamento e de autoquestionamento é fundamental para a reflexão, que não existe isolada, mas num processo de procura que ocorre no questionamento entre o que se pensa, a teoria que norteia a prática e o que se faz, ou seja, a própria prática.

Todos podem aprender uns com os outros, para isso é necessário momentos de formação e o comprometimento de cada professor com sua profissão de educador e de eterno aprendiz. Sendo assim,

é preciso considerar que o trabalho docente é essencialmente coletivo, uma vez que é realizado em um contexto em que vários outros sujeitos se fazem presentes, influenciam histórias de vida e são influenciados por elas, pelos valores, concepções, saberes e fazeres uns dos outros. Encontros de pequenos grupos, por série ou afinidade, podem sinalizar o início de um processo de organização importante, tendo em vista que grandes mudanças poderão surgir daí [...] (VEIGA, 2007, p. 142).

A formação realizada, proporcionou aos professores participantes o diálogo, a reflexão, a troca de ideias e experiências, propiciou também, conforme evidenciado nos relatos, a inspiração e motivação para querer aprender e buscar um maior aprofundamento nas teorias da educação, bem como a tornar "comum" práticas como essa no Colégio, pois eles mesmos relataram o quanto momentos como esse contribuem para a reflexão da prática docente. Veiga, (2007) observa que é preciso investir na 
formação continuada dos docentes como meio de acesso a conhecimentos, experiências e revisão de práticas, de maneira crítica e consciente, sendo a coordenação pedagógica o espaço privilegiado dessa formação.

Para finalizar essa reflexão, as pesquisadoras relatam, que a formação realizada possibilitou uma maior reflexão do fazer docente em sala de aula, e de um olhar mais atento do educador para a importância que a afetividade tem no processo de aprender e o quanto os jogos matemáticos propiciam a aprendizagem da matemática no Ensino Fundamental I, dois temas desenvolvidos durante a formação.

Imbernón (2011) observa que o conhecimento profissional consolidado mediante momentos de formação apoia-se tanto na obtenção de conhecimentos teóricos e de competências e rotinas, como no desenvolvimento de habilidades de processamento da informação, análise e reflexão crítica sobre a prática.

Nessa perspectiva, esta pesquisa poderá trazer contribuições para que profissionais da educação, tanto coordenadores, gestores, quanto professores, percebam a importância de momentos de formação continuada, contribuindo significativamente para a qualidade de ensino dentro das salas de aula, possibilitando um olhar mais crítico, atento e reflexivo do professor e de sua prática docente.

\section{REFERÊNCIAS}

ANDRÉ, M. et al. Estado da arte da Formação de Professores no Brasil.

Educação \& Sociedade, v. 20, n. 68, p. 301-309,1999.

ANDRÉ, M. Políticas de formação continuada e de inserção à docência no Brasil. Educação Unisinos, v. 19, n. 1, p. 34-44, 2015.

ARAÚJO, A. C. Gestão, avaliação e qualidade da educação: contradições e mediações entre políticas públicas e práticas escolar no Distrito Federal. 2011.xvi, 269 p. Tese (doutorado) - Universidade de Brasília, Faculdade de Educação, 2011. 
BRASIL. Constituição da República Federativa do Brasil de 1988. Disponível em: <http://www.planalto.gov.br/ccivil_03/constituicao/constituicao.htm>. Acesso em: 20 jan 2020.

BRASIL. Lei n 9.394, de 20 de dezembro de 1996. 1996. Disponível em: http://www.planalto.gov.br/ccivil_03/leis/19394.htm. Acesso em: 20 jan 2020.

BOGDAN, R, C.; BIKLEN, S. K. Investigação qualitativa em educação: uma introdução a teoria aos métodos. Porto: Porto Ed, 1994.

CAMPOS, E. C. A.; CARON, L. Formação Continuada e Permanente de Professores do Atendimento Educacional Especializado para Práticas Pedagógicas Inclusivas. São José, SC: ICEP, 2016.

ENGUITA, M. F. O discurso da qualidade e a qualidade do discurso. In: GENTILI, P. A. A.; SILVA, T. T. (Orgs.). Neoliberalismo, qualidade total e educação: visões críticas. 3 ed. Petrópolis: Vozes, 1994.

GARCIA, C. M. A formação de professores: novas perspectivas baseadas na investigação sobre o pensamento do professor. In: NÓVOA, A. (org.). Os professores e a sua formação. Lisboa: Dom Quixote: Instituto de Inovação Educacional, 1992.

GATTI, B. A. Educação, escola e formação de professores: políticas e impasses. Educar em Revista, Curitiba, n. 50, p. 51-67, 2013.

GATTI, B. A. (et al.). Professores no Brasil: novos cenários de formação. Brasília: UNESCO, 2019.

GENTILI, P. A. O discurso da "qualidade" como nova retórica conservadora no campo educacional. In: GENTILI, P. A.; SILVA, T. T. (Orgs.). Neoliberalismo, qualidade total e educação: visões críticas. 12. ed. Petrópolis: Vozes, 2007.

GUSMÃO, J. B. A construção da noção de qualidade em educação. Ensaio: aval. pol. públ. Educ., v. 21, n. 79, p. 299-322, 2013.

IMBERNÓN, F. Formação continuada de professores. Porto Alegre: Artmed, 2010.

IMBERNÓN, F. Formação docente e profissional: formar-se para a mudança e a incerteza. 9.ed. São Paulo: Cortez, 2011.

LÜCK, H. Gestão educacional: uma questão paradigmática. Petrópolis:

Vozes, 2006.

NETO, A. S.; SILVA, A. C. Panorama das pesquisas sobre formação continuada de professores nas reuniões da Anped entre os anos de 2000 e 
2018. In: IMBERNÓN, F.; NETO, S.; FORTUNATO, I. (Org.). Formação permanente de professores: experiências hiberoamericanas. São Paulo: Edições Hipótese, 2019.

NÓVOA, A. Professores: imagens do futuro presente. Lisboa: Educa, 2009.

NORONHA, E. C. S. F.; SARTORI, A. S.; SOUZA, A. R. B. (Org). Formação docente e práticas pedagógicas: cenários e trajetórias. Florianópolis: UDESC, 2010.

OLIVEIRA, R. P.; ARAUJO, G. C. Qualidade do ensino: uma nova dimensão da Iuta pelo direito à educação. Revista Brasileira de Educação, n. 28, p. 5-23, 2005.

ORSOLON, L. A. M. O coordenador/formador como um dos agentes de transformação da/na escola. In: ALMEIDA, L. R.; PLACCO, V. M. N. S. (Orgs.). O coordenador pedagógico e o espaço da mudança. 5 ed. São Paulo: Edições Loyola, 2006.

PLACCO, V. M. N. S.; ALMEIDA, L. R.; SOUZA, V. L. T. Retrato do coordenador pedagógico brasileiro: nuanças das funções articuladoras e transformadoras. In: PACCO, V. M. N. S.; ALMEIDA, L. R. (Orgs.). O coordenador pedagógico no espaço escolar: articulador, formador e transformador. São Paulo: Edições Loyola, 2015.

PLACCO, V. M. N. S.; SOUZA, V. L. T.; ALMEIDA, L. R. de. O coordenador pedagógico: aportes à proposição de políticas públicas. Cad.

Pesqui. [online], v.42, n. 147, p. 754-771, 2012.

PRADO, G. V. T (et al.). Formação de Professores em narrativas singulares. In: IMBERNÓN, F.; NETO, S.; FORTUNATO, I. (Org.). Formação permanente de professores: experiências hiberoamericanas. São Paulo: Edições Hipótese, 2019.

RAMOS, D. K. (Org.). Planejamento, participação e formação: conceitos e reflexões sobre os conselhos escolares. Florianópolis: Saberes em Diálogo, 2016.

SIQUEIRA, A. O. S.; AGUIAR, M. S.; COLARES, M. L. I. S. O processo de formação continuada de professores: ações do gestor escolar voltadas a transformação das práticas pedagógicas. Rev. EDUCA, v. 2, n. 3, p. 144-158, 2015.

SOUZA, V. L. T.; PLACCO, V. M. N. S. Entraves da formação centrada na escola: possibilidades de superação pela parceria da gestão na formação. In: ALMEIDA, L. R.; PLACCO, V. M. N. S. (Orgs.). O coordenador pedagógico e a formação centrada na escola. São Paulo: Edições Loyola, 2014. 
TEIXEIRA, E. As três metodologias: acadêmica, da ciência e da pesquisa. Petrópolis, RJ: Vozes, 2007.

VAILLANT, D. M., C. El ABC y D de La Formácion Docente. Madrid - Espanã. Narcea, S.A. de Ediciones, 2015.

VEIGA, I. P. A (org). Quem sabe faz a hora de Construir o Projeto PolíticoPedagógico. Campinas, SP: Papirus, 2007.

Recebido em: 07 de maio de 2020 Aprovado em: 15 de setembro de 2020 Publicado em: 17 de novembro de 2020

(c) (1) (8) 